\title{
Røyking og hjerte-kardødelighet
}

\author{
Aage Tverdal \\ Forskningsavdelingen, Statens helseundersøkelser, Postboks 8155 Dep, 0033 Oslo
}

\begin{abstract}
SAMMENDRAG
I en oppfølgingsstudie av 44374 menn og kvinner i alder 35-49 år var dødeligheten av hjerteinfarkt tre til fem ganger høyere blant sigarettrøykere enn blant aldri sigarettrøykere. Hos sigarettrøykere økte dødeligheten med økende antall sigaretter. Dødeligheten av hjerteinfarkt blant kvinner som røykte 20 sigaretter daglig var omtrent den samme som blant menn som aldri hadde røykt sigaretter. Hos menn ga røyking av annet enn sigaretter omtrent samme overdødelighet som røyking av sigaretter. For menn som også møtte til en undersøkelse tre til fem år senere var infarktdødeligheten hos dem som var røykere ved en av undersøkelsene og ikke-røykere ved den andre, mellom nivået for de som begge ganger enten var røykere eller ikke-røykere. For menn var infarktdødeligheten hos de som hadde sluttet å røyke for mer enn 5 år siden litt høyere enn hos aldri røykere, mens den hos kvinner var klart lavere. Dødeligheten av hjerneslag for sigarettrøykere lå to til fire ganger høyere enn den for aldri sigarettrøykere. For menn var det ingen sammenheng mellom antall sigaretter og slagdødelighet, mens det var en sammenheng for hjertefriske kvinner. Sigarettrøyking ga også en overdødelighet av andre kardiovaskulære sykdommer. For menn kom denne først til syne ved 20+ sigaretter.
\end{abstract}

Tverdal A. Smoking and cardiovascular mortality. Nor J Epidemiol 1995; 5 (2): 115-120.

\section{ENGLISH SUMMARY}

Altogether 44374 men and women 35-49 years old who attended a cardiovascular screening have been followed with respect to cardiovascular death for an average of 18.5 years. The screening was repeated 3-5 years later. Almost $90 \%$ of those invited attended. Smoking habits at the first screening and at both screenings were related to subsequent mortality. The main cardiovascular risk factors were adjusted for.

The risk of coronary death was three times higher in current compared to never cigarette smokers. Among persons without a history of cardiovascular disease, diabetes or symptoms of angina pectoris the relative risk was 3.6 in men and 4.8 in women. In current cigarette smokers the mortality increased with increasing number of cigarettes per day. The coronary heart disease mortality in women smoking 20 cigarettes was of the same order as that in men who had never smoked cigarettes. Men who were current non-cigarette smokers had almost the same excess risk as current cigarette smokers. The mortality in men having quit smoking more than 5 years ago was at nearly the same level as in never cigarette smokers, whereas it was much lower in women having given up smoking for $5+$ years. Men who changed smoking category between two screenings had a coronary heart disease mortality between that of the men who at both screenings were either smokers or non-smokers.

The relative risk of cerebrovascular disease between current and never cigarette smokers varied between 2.7 and 3.7. In men there was no relation with number of cigarettes, whereas in women a dose relationship was present among those without a history of cardiovascular disease, diabetes or symptoms of angina pectoris.

The mortality from other cardiovascular causes was also elevated among the cigarette smokers. In men this excess risk was seen only among smokers of $20+$ cigarettes per day.

\section{INTRODUKSJON}

En oppfølgingsstudie på sammenhengen mellom røykevaner og dødeligheten av en rekke årsaker er gjort tidligere (1). Denne studien fokuserer på hjertekardødelighet og atskiller seg fra den foregående ved at: 1) Oslostudien, som ikke er gjentatt, og Tromsøstudien ikke inngår, 2) røykevanene ved to undersøkelser blir utnyttet, 3) oppfølgingstiden er fire år lenger, 4) de som røyker svært få sigaretter er skilt ut som egen gruppe. 


\section{MATERIALE OG METODE}

Hjerte-karundersøkelser er gjennomført to ganger i Finnmark (1974-75 og 1977-78), Sogn og Fjordane (1975-76 og 1980-81) og Oppland (1976-78 og 198183). Beskrivelser av og omfattende resultater fra disse studier finnes i (2-4). Kort repeteres at samtlige bosatte $\mathrm{i}$ alder 35-49 år ble invitert første gang. Annen gang ble samtlige av disse som var bosatt $i$ disse fylker innkalt. I Finnmark betyr dette at eldste alder ved innkalling er 52 år ved andre undersøkelse, mens den er 54 år i de to andre fylker. Frammøtet var usedvanlig bra. Blant de som ble innkalt til begge undersøkelser møtte $88 \%$ begge ganger (4).

Informasjon om røykevaner ble innhentet via et selvutfylt spørreskjema som ble kontrollert for inkonsistenser ved frammøte. Gjengivelse av spørreskjemaet finnes i (2). Jeg vil operere med fire grupper: Aldri sigaretter ("Nei" på spørsmålet: "Røyker De daglig for tiden?" og "Nei" på spørsmålet: "Har De røykt sigaretter daglig tidligere?"), Sigaretter tidligere ("Nei" og "Ja" på de to forut siterte spørsmål), Ikke sigaretter nå ("Ja" på spørsmålet: "Røyker De daglig for tiden og "Nei" på spørsmålet: "Røyker De sigaretter daglig?"), Sigaretter nå ("Ja" på de to sist siterte spørsmål). Siste gruppe er ytterligere inndelt etter antall sigaretter: 0-4, 5-9, 10-19 og 20+. Personene ble bedt om å skrive inn antall sigaretter; det var ikke prekoding. I de tilfeller det er svart f.eks. 15-20 så er det høyeste antall benyttet.

Annen informasjon som er utnyttet i denne studien er kolesterol og systolisk blodtrykk. Metodene for måling og bestemmelse er beskrevet $\mathrm{i}(2,4)$. Videre ble det besvart spørsmål om hjerte-karsykdom, diabetes og symptomer på angina pectoris. Personer som svarte "Nei" på samtlige spørsmål: "Har De eller har De hatt: Hjerteinfarkt, Angina pectoris (hjertekrampe), Annen hjertesykdom, Åreforkalkning i bena, Hjerneslag, Sukkersyke", "Er De under behandling for Høyt blodtrykk", "Bruker De Nitroglyserin" og som hadde symptomsvar som ikke pekte i retning av Angina pectoris betegnes i denne studien som "Hjertefriske".

Dødelighetsoppfølgingen er fra tidspunkt for frammøte og ut 1992. To studiepopulasjoner er benyttet: De som møtte ved første undersøkelse og de som møtte både ved første og andre undersøkelse. For de som møtte begge ganger er oppfølgingen fra andre gangs frammøte og det er gjort analyser basert på røykeeksponeringen ved første undersøkelse, ved andre undersøkelse og både ved første og andre undersøkelse. I den sistnevnte situasjonen er ytterligere to røykegrupper definert: 1) de som svarte at de røykte første gang, men ikke andre gang, 2) de som svarte at de ikke røykte første gang, men andre gang.

Følgende dødsårsaker er studert: Hjerteinfarkt (ICD-9:410-413, 414.0-1, 414.3, 414.9), Karlesjoner i sentralnervesystemet (ICD-9:430-438), Annen kardio- vaskulær sykdom (ICD-9: Resten av 390-459). For tilsvarende ICD-8 koder konferer (1).

Absolutte dødelighetsrater per 100000 personår, ujustert, er beregnet. Videre er estimert relative risikoer ved Cox proporsjonal hazards regresjon. Alder, kolesterol og systolisk blodtrykk er inkludert som kovariable i tillegg til røykekategoriene som er definert som en rekke dummy variable, med de som aldri har røykt sigaretter som referanse. Ved oppfølging fra annen gangs undersøkelse er det i Cox regresjonen benyttet verdier fra annen gang for alder, kolesterol og systolisk blodtrykk.

\section{RESULTATER}

\section{Hjerteinfarkt}

Blant menn har ex-sigarettrøykere en koronardødelighet som ligger mellom den for de som aldri har røykt sigaretter og de som røyker nå (tabell 1). De som røyker annet enn sigaretter har samme risiko som de som røyker rundt 10 sigaretter daglig. Blant sigarettrøykere er det en stigende rate med økende antall. Menn som røyker kun 1-4 sigaretter har en høyere dødelighet enn ex-sigarettrøykere. Denne kontrasten er tydeligst blant de hjertefriske. Hvis vi anvender dødelighetsraten for de som aldri har røykt sigaretter på antall personår i hele studiepopulasjonen, får vi antall koronardødsfall vi kunne forventet hvis alle som møtte til undersøkelsen aldri hadde røykt sigaretter. Dette gir 318 dødsfall. Sammenholdes dette med de 895 koronardødsfall som faktisk inntraff får vi at $577(895-318)$ dødsfall, eller $64,5 \%$ av dødsfallene, kan tilskrives nåværende eller tidligere røyking.

Koronardødeligheten blant kvinner som har sluttet å røyke sigaretter er på samme nivå som for kvinner som aldri har røykt sigaretter (tabell 1). Blant sigarettrøykere er det en stigende tendens med økende dose, bortsett fra at dødeligheten for hjertefriske kvinner er den samme i de to høyeste dosekategorier. Det er få dødsfall i noen røykekategorier for kvinner. Tilsvarende beregning som for menn gir at $42,9 \%$ av koronardødsfallene blant kvinner kan tilskrives røyking nå eller tidligere.

Det bemerkes at menn som aldri har røykt sigaretter har tilnærmelsesvis den samme koronardødelighet som kvinner som røyker 20 eller flere sigaretter per dag.

\section{Karlesjoner i sentralnervesystemet (hjerneslag)}

Dødeligheten er høyere for de som røyker sigaretter enn de som ikke røyker (tabell 1). Blant ikke-røykere er det liten forskjell mellom aldri og tidligere sigarettrøykere, faktisk er dødeligheten gjennomgående litt høyere for de som aldri har røykt sigaretter. Blant sigarettrøykere er det ingen dose-respons sammenheng bortsett fra blant hjertefriske kvinner. Menn 


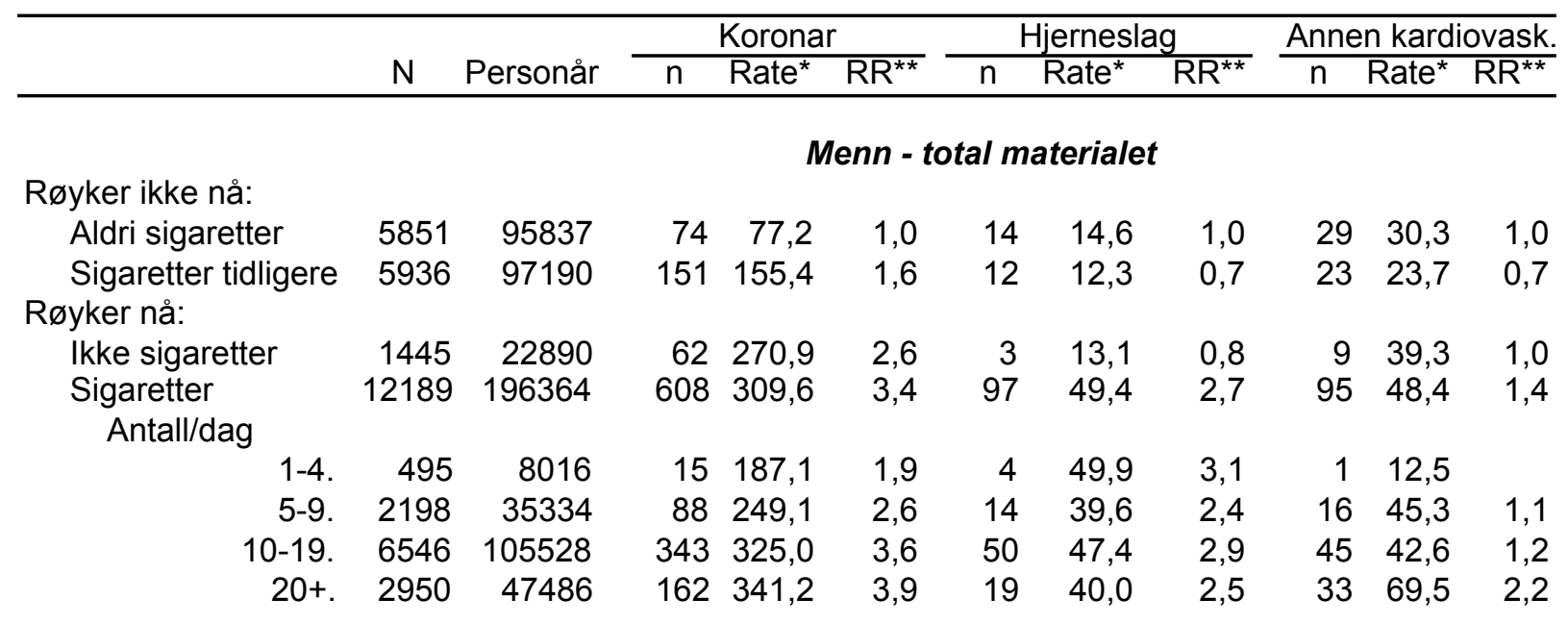

Røyker ikke nå:

Aldri sigaretter

5475

89960

$56 \quad 62,2$

Menn - hjertefriske

Sigaretter tidligere $\quad 5340 \quad 87904$

Røyker nå:

$\begin{array}{lrr}\text { lkke sigaretter } & 1341 & 21339 \\ \text { Sigaretter } & 11029 & 178966\end{array}$

8192,1

$\begin{array}{rrr}1,0 & 13 & 14,5\end{array}$

$\begin{array}{llll}1,0 & 20 & 22,2 & 1,0\end{array}$

$\begin{array}{lllllllll}48 & 224,9 & 2,8 & 3 & 14,1 & 0,8 & 5 & 23,4 & 0,8\end{array}$

Antall/dag

$\begin{array}{rrr}1-4 . & 445 & 7262 \\ 5-9 . & 1990 & 32304 \\ 10-19 . & 5958 & 96740 \\ 20+. & 2636 & 42660\end{array}$

454253,7

$3,6 \quad 61$

$12 \quad 165,2 \quad 2,3$

59182,6

2,4

$\begin{array}{ll}3 & 41,3\end{array}$

2,1

$\begin{array}{lll}64 & 35,8 & 1,4\end{array}$

253261,5

$\begin{aligned} & 2,4,7-9 \\ & 3,7\end{aligned}-4,9$

2,6

$\begin{array}{llll}1,7 & 11 & 34,1 & 1,1\end{array}$

130304,7

$3,7 \quad 41 \quad 42,4 \quad 2,6$

$31 \quad 32,0 \quad 1,3$

Kvinner - total materialet

Røyker ikke nå:

Aldri sigaretter

$12517 \quad 207684$

$\begin{array}{lllll}45 & 21,7 & 1,0 & 30 & 14,4\end{array}$

1,0

$23 \quad 11,1 \quad 1,0$

Sigaretter tidligere $3128 \quad 51593$

Røyker nå:

Ikke sigaretter

Sigaretter

Antall/dag

$\begin{array}{rr}11 & 180 \\ 9148 & 150683\end{array}$

1

99

$\begin{array}{rrr}1-4 . & 898 & 14851 \\ 5-9 & 3080 & 50810\end{array}$

$\begin{array}{lllll}7 & 47,1 & 2,2 & 6 & 40,4\end{array}$

$\begin{array}{lllll}31 & 61,0 & 2,8 & 18 & 35,4\end{array}$

35,4
43,1

0,7

$6 \quad 11,6 \quad 1,0$

10-19. $4514 \quad 74303$

5168,6

$3,2 \quad 32$

43,1
37,3

$3, \overline{0}$

$2 \overline{-} \quad 17, \overline{9} \quad 1, \overline{8}$

20+. $656 \quad 10719$

1093,3

Kvinner - hjertefriske

Røyker ikke nå:

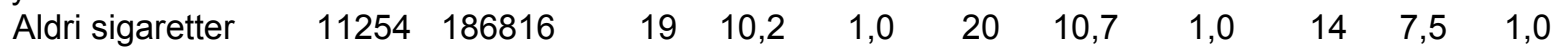

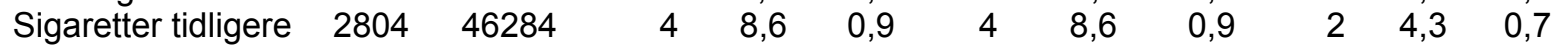

Røyker nå:

Ikke sigaretter $\quad 8 \quad 133$

Sigaretter

8291136655

Antall/dag

1-4. $\quad 814 \quad 13481$

5-9. $2801 \quad 46245$

$\begin{array}{rrr}10-19 . & 4101 & 67489 \\ 20+ & 575 & 9440\end{array}$

$\begin{array}{lll}2,9 & 1 & 6,7\end{array}$

$\begin{array}{lll}2,7 & 10 & 19,7\end{array}$

$\begin{array}{lll}3,3 & 13 & 17,5\end{array}$

$\begin{array}{llll}3,0 & 3 & 28,0 & 1,8\end{array}$

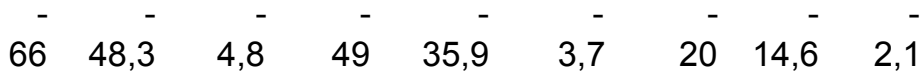

$\begin{array}{llllllll}3 & 22,3 & 2,3 & 4 & 29,7 & 2,9 & 1 & 7,4\end{array}$

$\begin{array}{lllllllll}21 & 45,4 & 4,5 & 15 & 32,4 & 3,2 & 5 & 10,8 & 1,5\end{array}$

$\begin{array}{llllllll}37 & 54,8 & 5,5 & 26 & 38,5 & 4,1 & 13 & 19,3\end{array}$

\begin{tabular}{lllllllll}
5 & 53,0 & 5,5 & 4 & 42,4 & 4,5 & 1 & 10,6 & 2,7 \\
\hline
\end{tabular}

* Per 100000 personår

${ }^{* *}$ Relativ risiko estimert ved Cox proporsjonal hazards regresjon justert for alder, kolesterol og systolisk blodtrykk 
som røyker annet enn sigaretter har samme dødelighet som ikke-røykere. Justert for andre risikofaktorer er risikoen noe lavere enn blant menn som aldri har røykt sigaretter. For menn kan 52,4\% og for kvinner kan $37,9 \%$ av slagdødsfallene tilskrives nåværende eller tidligere røyking.

\section{Annen kardiovaskulaer sykdom}

Dødeligheten er også for denne årsaksgruppen noe lavere for ex- enn for aldri-sigarettrøykere bortsett fra i totalmaterialet for kvinner. Blant sigarettrøykere er det ingen uttalt dose-respons, men det pekes på en høyere dødelighet i gruppen $20+$ sigaretter blant menn. For menn og kvinner kan henholdsvis 19,9\% og 17,9\% av dødsfallene av annen kardiovaskulær sykdom tilskrives røyking nå eller tidligere.

Koronardødeligheten avtar med tid siden røykeslutt hos menn som har sluttet for mer enn ett år siden (tabell 2). For kvinner er det kun ti dødsfall blant ex-sigarettrøykere. Imidlertid er antall personår i gruppa som har sluttet for mer enn fem år siden like stort som antall personår $\mathrm{i}$ de tre andre grupper tilsammen.

Tabell 3 gir resultatet av en oppfølging mot koronardød fra undersøkelse II for de menn som møtte både til undersøkelse I og II. Tre bolker er presentert:

1. basert på røykeeksponering ved undersøkelse I

2. eksponering ved undersøkelse II

3. røykeeksponering ved undersøkelse I og II

Tabell 2. Koronardødelighet etter tid siden røykeslutt. Menn og kvinner 35+ år ved undersøkelse I som har røykt tidligere

\begin{tabular}{|c|c|c|c|c|c|c|c|c|c|}
\hline \multirow{2}{*}{$\begin{array}{l}\text { Tid siden } \\
\text { røykeslutt }\end{array}$} & & \multicolumn{4}{|c|}{ Menn } & \multicolumn{4}{|c|}{ Kvinner } \\
\hline & & Personår & $\mathrm{n}$ & Rate $^{*}$ & $\mathrm{RR}^{* *}$ & Personår & $\mathrm{n}$ & Rate $^{*}$ & $\mathrm{RR}^{\star *}$ \\
\hline & $\begin{array}{l}\text { 1-3 mndr. } \\
\text { 3-12 mndr. }\end{array}$ & $\begin{array}{r}7157 \\
11204\end{array}$ & $\begin{array}{l}17 \\
31\end{array}$ & $\begin{array}{l}238 \\
277\end{array}$ & $\begin{array}{l}2,4 \\
2,8\end{array}$ & $\begin{array}{l}5773 \\
6400\end{array}$ & $\begin{array}{l}0 \\
3\end{array}$ & 47 & 1,2 \\
\hline & 1-5 år & 29203 & 41 & 140 & 1,5 & 13712 & 6 & 44 & 1,9 \\
\hline & $5+$ år & 49298 & 59 & 120 & 1,2 & 25505 & 1 & 4 & 0,2 \\
\hline
\end{tabular}

* Per 100000 personår

** Relativ risiko estimert ved Cox proporsjonal hazards regresjon justert for alder, kolesterol og systolisk blodtrykk og med "Aldri sigarettrøykere" som referanse

Tabell 3. Koronardødelighet etter røykevaner. Menn 35+ år ved undersøkelse I som har møtt både til undersøkelse I og II. Oppfølging fra undersøkelse II

\begin{tabular}{rrrrr}
\hline & Personår & $\mathrm{n}$ & Rate & $\mathrm{RR}^{\text {* }}$ \\
\hline Aldri sigaretter & 63682 & Undersøkelse I & \\
Tidligere sigaretter & 65341 & 127 & 194,4 & 1,0 \\
Røyker nå & 146572 & 534 & 364,3 & 2,9 \\
& \multicolumn{4}{c}{ Undersøkelse II } \\
Aldri sigaretter & 66209 & 80 & 120,8 & 1,0 \\
Tidligere sigaretter & 81491 & 158 & 193,9 & 1,4 \\
Røyker nå & 127852 & 490 & 383,3 & 2,8 \\
& \multicolumn{4}{c}{ Undersøkelse I og II } \\
Aldri sigaretter & 59754 & 66 & 110,5 & 1,0 \\
Tidligere sigaretter & 3979 & 6 & 150,8 & 1,4 \\
Røyker nå & 118887 & 463 & 389,4 & 3,2 \\
Røyker I, ikke-røyker II & 27684 & 71 & 256,5 & 2,0 \\
Ikke-røyker I, røyker II & 8964 & 27 & 301,2 & 2,6 \\
\hline
\end{tabular}

* Relativ risiko estimert ved Cox proporsjonal hazards regresjon justert for alder, kolesterol og systolisk blodtrykk ved undersøkelse II 
Relativ risiko for ex-sigarettrøykere og nåværende røykere i forhold til aldri-sigarettrøykere er nær den samme $\mathrm{i}$ alle tre kolonner. Videre har de som rapporterte røyking ved I og ikke-røyking ved II en koronardødelighet som ligger midt mellom den for aldri sigaretter og nåværende røykere. Gruppa som har gått den motsatte veien fra ikke-røyking ved I til røyking ved II har nærmet seg, men ikke helt nådd, nivået for nåværende røykere.

\section{DISKUSJON}

Daglig sigarettrøyking ga forhøyet risiko for dødelighet av hjerteinfarkt, hjerneslag og andre kardiovaskulære årsaker hos middelaldrende menn og kvinner. Andelen dødsfall som kan tilskrives røyking var størst for hjerteinfarkt og større for menn enn for kvinner. Blant sigarettrøykere framstod en klar sammenheng mellom antall sigaretter og dødelighet av hjerteinfarkt. Menn som hadde sluttet å røyke sigaretter for mer enn fem år siden hadde en dødelighet av hjerteinfarkt som var nær nivået for de som aldri har røykt sigaretter, mens kvinner som hadde sluttet for mer enn fem år siden hadde en lavere dødelighet enn aldri sigarettrøykere. Blant menn som møtte til to undersøkelser lå koronardødeligheten for de som hadde endret sine røykevaner mellom nivået for ikkerøykere og røykere.

Den relative risiko for koronardød mellom gruppene 20+ og 1-4 sigaretter er av samme størrelsesorden som den relative risiko mellom gruppene 1-4 sigaretter og ikke-røykere. Lund Håheim og medarbeidere (5) fant sågar at kontrasten (på relativ skala) var langt mindre mellom menn som rapporterte 1-4 sigaretter og menn som var ikke-røykere enn kontrasten mellom menn som røykte mange og menn som røykte få sigaretter. På den annen side er ratedifferansen (absolutt skala) i vår studie størst mellom de to sigarettkategorier. Hva som gir størst koronar risikoøkning: å gå fra å være ikke-røyker til små-røyker eller: å gå fra å være små-røyker til å være storrøyker synes altså å være avhengig av den skalaen man måler risikoøkning på.

Lenger oppfølgingstid har gitt mer presise estimater for kvinner og den relative risikoøkning knyttet til sigarettrøyking er helt klar. For hjertefriske er endog den koronare relative risiko for sigarettrøykere høyere for kvinner enn for menn.

Det er interessant å sette sigarettrøyking som risikofaktor i relasjon til utviklingen over tid i dødelighet av hjerteinfarkt. Dødeligheten har gått tilbake fra rundt 1970, mens røykevanene har endret seg lite; for kvinner har det vært en stadig økende andel av 40åringene som har røykt (6-8). Det er noe gåtefullt, men gledelig, å konstatere at hjerteinfarktdødeligheten har gått tilbake til tross for at en av de sentrale risikofaktorer har endret seg lite.

Den viktigste risikofaktoren, nemlig kolesterol, har imidlertid stadig lavere gjennomsnittsnivå i de nye generasjoner av 40-åringer $(7,8)$. Man kunne tenke seg at effekten av røyking på koronardødeligheten var mindre ved lave nivåer av kolesterol. Dette er framsatt som mulig forklaring på den lave koronardødeligheten i Japan, til tross for at andelen som røyker der er høy. Vi har prøvd å utrede dette med norske data, men få dødsfall ved lave kolesterolnivåer ga upresise estimater (9). Det var imidlertid en klar tendens til mindre effekt av røyking ved kolesterol under $5 \mathrm{mmol} / \mathrm{l}$, men effekten forsvant ikke.

Dødeligheten av hjerteinfarkt for menn som rapporterte å ha sluttet å røyke for mer enn fem år siden var nesten nede på nivået for aldri-røykere. Tendensen til en avtagende dødelighet med økende tid siden røykeslutt var klar bortsett fra i de to første tidsperioder. For kvinner bemerkes en svært lav hjerteinfarktdødelighet i gruppen som hadde sluttet å røyke for mer enn fem år siden. Det er riktignok kun et dødsfall, men antall personår i denne gruppen er like stort som i de tre andre grupper tilsammen. Disse kvinner er trolig en selektert lavrisikogruppe.

Gruppen som har rapportert sigaretter tidligere ved både undersøkelse I og II er svært liten. Dette tyder på at en god del av de som rapporterer å ha sluttet ved en enkelt undersøkelse begynner å røyke igjen. Dødelighetsratene (tabell 3) for de som har endret røykevaner mellom to undersøkelser er forenlig med at disse grupper faktisk svinger i sine røykevaner i stor grad.

Denne studien kan tyde på at relasjonen mellom røykevaner og dødelighet atskiller seg for hjerteinfarkt og hjerneslag på to måter:

1. Blant sigarettrøykere synes det ikke å være en dose-respons sammenheng for hjerneslag, mens den nå er tydelig for koronardød.

2. Slagdødeligheten later ikke til å være assosiert med andre typer røyk enn sigaretter.

Den tidligere studie med Oslo og Tromsø inkludert (1) viste for menn ingen dose-sammenheng for subarachnoidalblødning mens det var en dosesammenheng for andre cerebrovaskulære årsaker. For kvinner var tendensen den samme, men sammenhengen med antall sigaretter var ikke signifikant hverken for subarachnoidalblødning eller andre cerebrovasculære årsaker. Muligheten for forskjellig dosesammenheng for forskjellige cerebrovaskulære årsaker må holdes åpen. Hvorvidt sigaretter er mye ugunstigere enn annen type røyking hva angår risiko for slagdød bør studeres ytterligere. Det kan også tenkes at menn som røyker noe annet enn sigaretter er en selektert lavrisikogruppe med hensyn til slagdød. På den annen side er en slik seleksjonshypotese vanskelig å forene med at det ikke er lavere risiko for koronardød. 


\section{REFERANSER}

1. Tverdal A, Thelle D, Stensvold I, Leren P, Bjartveit K. Mortality in relation to smoking history: 13 years' follow-up of 68,000 Norwegian men and women 35-49 years. J Clin Epidemiol 1993; 46: 47587.

2. Bjartveit K, Foss OP, Gjervig T, Lund-Larsen PG. The cardiovascular disease study in Norwegian counties. Background and organization. Acta Med Scand 1979; suppl No 634: 1-70.

3. Bjartveit K, Foss OP, Gjervig T. The cardiovascular disease study in Norwegian counties. Results from first screening. Acta Med Scand 1983;suppl No 675:1-184.

4. National Health Screening Service, Health Services of Finnmark, Sogn og Fjordane and Oppland counties, Ullevål Hospital, Central Laboratory, Oslo. The cardiovascular disease study in Norwegian counties. Results from second screening. National Health Screening Service 1988.

5. Lund Håheim L, Holme I, Hjermann I, Leren P. The predictability of risk factors with respect to incidence and mortality of myocardial infarction and total mortality. A 12-year follow-up of the Oslo Study, Norway. J Int Med 1993; 234: 17-24.

6. Tverdal A. Hjerte-kar epidemiologi. Nor J Epidemiol 1993; 2: 4-7.

7. Bjartveit K, Stensvold I, Lund-Larsen PG, Graff-Iversen S, Urdal P. Hjerte- og karundersøkelser i norske fylker. Utvikling 1985-90 av risikomønster blant 40-42 åringer i fire fylker. Tidskr Nor Lageforen 1991; 111: 2072-6.

8. Statens helseundersøkelser. Hjertesaken. 1985-1995 (Utgis etter hver undersøkelsesrunde i hvert fylke).

9. Tverdal A, Stensvold I. Is there an effect of smoking on coronary heart disease mortality at low levels of cholesterol? Eur Heart J 1995;16 Abstr. Suppl. XVIIth Congress of the European Society of Cardiology - P482. 